University of Massachusetts Amherst

ScholarWorks@UMass Amherst

2001

\title{
On-line matrix removal of lead for the determination of trace elements in forensic bullet samples by flow injection inductively coupled plasma-mass spectrometry
}

ER Yourd

JF Tyson

RD Koons

Follow this and additional works at: https://scholarworks.umass.edu/chem_faculty_pubs

Part of the Chemistry Commons

\section{Recommended Citation}

Yourd, ER; Tyson, JF; and Koons, RD, "On-line matrix removal of lead for the determination of trace elements in forensic bullet samples by flow injection inductively coupled plasma-mass spectrometry" (2001). Spectrochimica Acta Part B-Atomic Spectroscopy. 1036.

Retrieved from https://scholarworks.umass.edu/chem_faculty_pubs/1036 


\title{
On-line matrix removal of lead for the determination of trace elements in forensic bullet samples by flow injection inductively coupled plasma-mass spectrometry
}

\author{
Emily R. Yourd ${ }^{a}$, Julian F. Tyson ${ }^{\mathrm{a}, *}$, Robert D. Koons ${ }^{\mathrm{b}}$ \\ ${ }^{a}$ Department of Chemistry, University of Massachusetts, 710 N. Pleasant Street, Amherst, MA 01003-9306, USA \\ ${ }^{\mathrm{b}}$ Forensic Science Research Unit, FBI Academy, FSRTC, Quantico, VA 22135, USA
}

Received 14 March 2001; accepted 13 June 2001

\begin{abstract}
The determination of trace elements in lead by inductively coupled plasma (ICP) source mass spectrometry (MS) is not possible without the removal of a substantial proportion of the lead matrix. This was achieved by the retention of lead from a $130-\mu \mathrm{l}$ sample solution ( $100 \mathrm{mg} \mathrm{l}^{-1}$ lead in $2 \% \mathrm{v} / \mathrm{v}$ nitric acid) injected into a single-line (3\% v/v nitric acid) flow injection manifold, on $100 \mathrm{mg}$ of $\mathrm{Pb}-\mathrm{Spec}^{\circledR}$ packed into a cylindrical column $(6 \mathrm{~cm} \times 4 \mathrm{~mm}$ internal diameter). The analytes, $\mathrm{Ag}, \mathrm{As}, \mathrm{Bi}, \mathrm{Cd}, \mathrm{Cu}, \mathrm{Sb}$ and $\mathrm{Sn}$, passed through the column and were quantified against matrix-matched standards. Only Ag showed significant retention, but could still be measured in an 8-min run. The column was rinsed by flushing with $0.1 \mathrm{M}$ ammonium citrate solution. Lead was monitored by flame atomic absorption spectrometry in preliminary experiments concerning column capacity and breakthrough. Although the capacity of the material in the dynamic, flow-through mode was less than the literature value based on equilibrium studies, the lead from up to 13 successive injections was sufficiently retained to allow accurate determination of the analytes without intermediate rinsing of the column. The precision [percentage relative standard deviation (\%R.S.D.), $n=5$ ] of the procedure ranged from $1.7 \%$ (100 $\mathrm{ng} \mathrm{ml}^{-1}$ copper) to $2.8 \%\left(5 \mathrm{ng} \mathrm{ml}^{-1}\right.$ cadmium), and detection limits were in the range $0.2-10 \mathrm{ng} \mathrm{ml}^{-1}$. The accuracy of the procedure was assessed by the analysis of three National Institute of Standards and Technology standard reference materials (SRM 2416 bullet lead, SRM 2415 battery lead, and SRM 2417 lead base alloy). For each SRM, duplicate determinations of seven analytes were made. Of the 42 determinations, 36 fell within the confidence interval around the accepted value. Three real bullets were analyzed for seven elements by both the flow injection solid-phase extraction ICP-MS method and by aspiration of the bullet solutions (10000 $\mathrm{mg}^{-1}$ lead) directly into an ICP emission spectrometer. A linear least squares regression of these
\end{abstract}

\footnotetext{
* Corresponding author. Tel.: + 1-413-545-0195; fax: + 1-413-545-4846;

E-mail address: tyson@chem.umass.edu(J.F. Tyson).
} 
two sets of results gave a line with slope $1.01 \pm 0.04$ and an intercept of $-5 \pm 100 \mu \mathrm{g} \mathrm{g}^{-1}$, where the \pm terms are $95 \%$ confidence intervals. The column lifetime was in excess of 5 months of daily use.

Keywords: Flow injection; Solid phase extraction; Lead; Matrix removal; Inductively coupled plasma-mass spectrometry

\section{Introduction}

The trace element composition of bullet lead can provide important information to law enforcement personnel attempting to solve firearms-related crimes. This examination becomes even more crucial in situations where a firearm is not recovered or the crime scene bullet is too mutilated for conventional ballistics identification [1]. In these cases, the composition of the evidence bullet is compared with unfired bullets that can be associated with a suspect. The conclusion from this type of comparison is that the composition of the crime scene bullet is either analytically distinguishable or indistinguishable with that of bullets from a known source [2].

The compositional analysis of bullet lead has been performed by a variety of instrumental methods. These include neutron activation analysis (NAA), atomic absorption spectrometry (AAS), spark source mass spectrometry (SSMS), inductively coupled plasma atomic emission spectrometry (ICP-AES), and inductively coupled plasma mass spectrometry (ICP-MS) [1,2]. Each technique has its advantages and disadvantages. Neutron activation analysis and AAS are both limited by the number of elements of interest that can be determined conveniently, while the spark source and plasma methods are susceptible to interferences from the sample matrix. However, NAA and ICP-AES methods have been used extensively, particularly by the FBI Laboratory, and have been applied to thousands of cases over the past 30 years.

The multielement capability, sensitivity, and dynamic range of ICP-MS make this the ideal technique for trace element analyses of bullet lead. The most significant analytical disadvantage to using ICP-MS, however, is the interference caused by the lead in the sample matrix. Because bullets typically contain 95-99\% lead [3], sample solutions must be diluted extensively to avoid the signal suppression and salt deposition resulting from the presence of the matrix. However, this dilution makes the target elements more difficult to detect. Thus, a suitable procedure would be to remove the interfering lead matrix without decreasing the concentrations of the analytes.

The selective removal of a matrix element is not a commonly performed procedure. One laboratory removed the lead from bullet digests by precipitating the $\mathrm{Pb}$ as its sulfate [2]. Although this off-line technique appears successful, the throughput is reduced by the requisite 1-h delay to ensure complete precipitation. Another report [4] describes the removal of a uranium matrix from a sample by utilizing the selectivity of solidphase extraction resins. The sample was injected into a flow injection manifold containing an ionexchange column that retained the matrix while allowing the analytes to pass through unretained.

The affinity of macrocyclic crown ethers for specific cations is well known [5-8]. Those cations with ionic radii most closely matching that of the macrocycle's cavity will be selectively complexed by the ether. Cations that are significantly smaller than the cavity will be too far from the ring oxygens' lone pairs to form an appreciable bond, while larger cations will not be able to fit inside the cavity at all. The selectivity of crown ethers can be used to separate certain cations from a mixture, both for preconcentration purposes and for matrix removal [9-14].

A solid-phase extraction (SPE) material containing immobilized di-t-butyl-dicyclohexano-18crown- 6 was incorporated into a flow injection manifold. This crown ether, known as $\mathrm{Pb}-\mathrm{Spec}^{\circledR}$ is selective for and has a high capacity for lead $[9,10,13]$. An on-line solid-phase extraction 
method has been developed for the selective retention of lead from bullet samples with subsequent determination of $\mathrm{Ag}, \mathrm{As}, \mathrm{Bi}, \mathrm{Cd}, \mathrm{Cu}, \mathrm{Sb}$ and Sn by ICP-MS.

\section{Experimental}

\subsection{Reagents and standards}

$\mathrm{Pb}-\mathrm{Spec}$ resin was obtained from Eichrom, Inc. (Darien, IL, USA) and used as received. A stock solution of $1000 \mu \mathrm{g} \mathrm{ml}^{-1} \mathrm{~Pb}$ was prepared by dissolving the appropriate amount of lead nitrate in $2 \% \mathrm{HNO}_{3}$. A stock solution containing $100 \mu \mathrm{g}$ $\mathrm{ml}^{-1} \mathrm{Sb}, 10 \mu \mathrm{g} \mathrm{ml}^{-1} \mathrm{Bi}, \mathrm{Cu}$ and $\mathrm{Sn}, 7.5 \mu \mathrm{g} \mathrm{ml}^{-1}$ As, $1 \mu \mathrm{g} \mathrm{ml}^{-1} \mathrm{Ag}$, and $0.5 \mu \mathrm{g} \mathrm{ml}^{-1} \mathrm{Cd}$ was prepared by the appropriate dilution of $1000 \mu \mathrm{g}$ $\mathrm{ml}^{-1}$ atomic absorption standards of the individual elements (PE Pure or Spex) with $20 \% \mathrm{HNO}_{3}$ (Optima grade, Fisher). Two working solutions were prepared by a 100 -fold dilution of the stock with $2 \% \mathrm{HNO}_{3}$; one solution was also spiked with $\mathrm{Pb}$ to a final concentration of $100 \mu \mathrm{g} \mathrm{ml}^{-1}$. Calibration standards were prepared by diluting the lead-containing solution while keeping the $\mathrm{Pb}$ concentration constant at $100 \mu \mathrm{g} \mathrm{ml}^{-1}$. In some instances, this required the addition of $\mathrm{Pb}$ from a $1000-\mu \mathrm{g} \mathrm{ml}^{-1} \mathrm{~Pb}$ atomic absorption standard (PE Pure). The carrier solution was $3 \% \mathrm{HNO}_{3}$, while the eluent was $0.1 \mathrm{M}$ ammonium citrate solution of $\mathrm{pH}$ 5.23. All solutions were prepared using deionized water with a resistivity of $18.2 \mathrm{M} \Omega$ (Milli-Q, Millipore), and stored in acid-washed polyethylene (Nalgene) bottles.

\subsection{Apparatus}

Two flame atomic absorption spectrometers were used for method development. These were both Perkin-Elmer (Norwalk, CT, USA) instruments: a model 1100B with deuterium background correction, and a model 3100 . Both instruments were equipped with a Perkin-Elmer lead hollow cathode lamp and were operated under the manufacturer's recommended conditions. The $10-\mathrm{cm}$ air-acetylene burner head position was optimized in three dimensions while aspirating a solution containing $20 \mu \mathrm{g} \mathrm{ml}^{-1} \mathrm{~Pb}$ in $2 \% \mathrm{HNO}_{3}$. When the flow injection manifold was used for sample introduction, the capillary of the nebulizer was positioned in the venturi throat in such a way that the nebulizer suction was zero. This ensured that the pumps controlled the flow rate of the solution entering the spray chamber. The 1100B instrument was used in the hold mode, integrating over $5 \mathrm{~s}$ with 10 replicates. This produced absorbance values spaced evenly over $50 \mathrm{~s}$. The 3100 instrument was operated in the continuous mode with an Epson LQ-850 printer for data collection.

The sample analysis was performed with an inductively coupled plasma mass spectrometer, HP4500 ICP-MS (Agilent Technologies, Inc., Wilmington, DE, USA) equipped with a cross-flow nebulizer and Peltier-cooled Scott-type spray chamber. The instrument was tuned at least daily while aspirating a solution of $10 \mathrm{ng} \mathrm{ml}^{-1} \mathrm{Ce}, \mathrm{Li}$, $\mathrm{Tl}$ and $\mathrm{Y}$ in $5 \% \mathrm{HNO}_{3}$. The instrumental conditions are listed in Table 1. The instrument's peristaltic pump was used only for spray chamber draining, and was operated at a flow rate of approximately $2.0 \mathrm{ml} \mathrm{min}^{-1}$. The time-resolved mode was used, with $0.3 \mathrm{~s}$ residence time per mass, and a total analysis time of $8 \mathrm{~min}$. Multiple isotopes were determined for each element.

Data from the mass spectrometer was collected using HP ICP-MS software v.4 and processed with HP ICP-MS Chromatographic software v.4 on a Hewlett-Packard Kayak personal computer. Additional data analysis was performed using PeakFit v.4.05 (AISN Software, Inc.) for the calculation of peak areas. The baseline was subtracted from the peaks, but the data were used without any smoothing. This processing was done on a personal computer using Microsoft Excel 97, which was also used to obtain the calibration equations by unweighted least-squares regression.

Comparison sample analysis was performed with an Optima 3300DV inductively coupled plasma atomic emission spectrometer (PerkinElmer, Norwalk, CT, USA). Daily initiation and calibration checks were performed according to the manufacturer's recommendations; samples were arranged in the instrument's autosampler, sequentially aspirated into the nebulizer at a flow 
Table 1

Operating conditions for the HP4500 ICP-MS and Optima 3300DV ICP-AES instruments

\begin{tabular}{|c|c|c|}
\hline & ICP-MS & ICP-AES \\
\hline Rf power, W & 1200 & 1400 \\
\hline \multicolumn{3}{|l|}{ Argon gas flow: } \\
\hline Plasma gas flow rate, $1 \mathrm{~min}^{-1}$ & 15.2 & 15 \\
\hline Auxiliary gas flow rate, $1 \mathrm{~min}^{-1}$ & & 0.3 \\
\hline Carrier gas flow rate, $1 \mathrm{~min}^{-1}$ & 1.06 & 0.6 \\
\hline Sample and skimmer cones & Nickel & \\
\hline Spray chamber temperature, ${ }^{\circ} \mathrm{C}$ & 2 & Ambient \\
\hline \multicolumn{3}{|l|}{ Data acquisition parameters } \\
\hline Mode & Time resolved & \\
\hline Dwell time, $\mathrm{s}$ & 0.3 & \\
\hline Sampling period, s & 4.3 & \\
\hline Number of points per mass & 114 & \\
\hline Total analysis time per replicate, $\mathrm{s}$ & 480 & 10 \\
\hline Number of replicates & 1 & 3 \\
\hline Viewing height, mm & 6.2 & 15 \\
\hline \multirow[t]{7}{*}{ Isotopes or analytical wavelengths, $\mathrm{nm}$} & ${ }^{63} \mathrm{Cu},{ }^{65} \mathrm{Cu}$, & $\mathrm{Ag} / 328.1$ \\
\hline & ${ }^{75} \mathrm{As},{ }^{107} \mathrm{Ag}$ & As $/ 189.0$ \\
\hline & ${ }^{109} \mathrm{Ag},{ }^{111} \mathrm{Cd}$ & $\mathrm{Bi} / 223.1$ \\
\hline & ${ }^{113} \mathrm{Cd},{ }^{116} \mathrm{Sn}$, & $\mathrm{Cd} / 214.4$ \\
\hline & ${ }^{118} \mathrm{Sn},{ }^{120} \mathrm{Sn}$ & $\mathrm{Cu} / 324.8$ \\
\hline & ${ }^{121} \mathrm{Sb},{ }^{123} \mathrm{Sb}$ & $\mathrm{Sb} / 206.8$ \\
\hline & ${ }^{209} \mathrm{Bi}$ & $\mathrm{Sn} / 190.0$ \\
\hline
\end{tabular}

rate of $1.5 \mathrm{ml} \mathrm{min} \mathrm{m}^{-1}$, and measured in triplicate. Additional instrument operating conditions are listed in Table 1.

The flow injection manifold consisted of two peristaltic pumps (Ismatec), two six-port rotary valves, and lengths of tubing. The manifold is shown schematically in Fig. 1. The sample injection volume was $130 \mu \mathrm{l}$, and the SPE column was in the loop of the second valve. The three-stop Tygon pump tubing used for both pumps had an internal diameter of $1.52 \mathrm{~mm}$ (blue-yellow). All other tubing was $0.8 \mathrm{~mm}$ i.d. PTFE. The glass SPE column was $6 \mathrm{~cm}$ long with an i.d. of $4 \mathrm{~mm}$. A complete list of the values of the relevant parameters used in the analyses is given in Table 2. The tubing lengths between the SPE column and the ICP-MS were minimized.

\subsection{Method development}

The purpose of this study was to investigate the feasibility of matrix removal for the compositional analysis of bullet lead by ICP-MS, so a limited optimization was carried out. Starting values for the relevant parameters were available from previous work on the behavior of Pb-Spec [9]. The ammonium citrate concentration was used as recommended [9] and remained unchanged throughout the experiments. The figures of merit selected for investigation were the lead capacity of the resin, the ability of the resin to strip lead as a function of carrier acidity, and sample volume.

Table 2

Optimized operating conditions for the flow injection manifold

\begin{tabular}{|c|c|}
\hline Parameter & Value \\
\hline Pump tubing & $1.52 \mathrm{~mm}$ internal diameter (blue-yellow) \\
\hline SPE column & $6 \mathrm{~cm}$ long $\times 4 \mathrm{~mm}$ internal diameter \\
\hline Mass of $\mathrm{Pb}-\mathrm{Spec}$ & $100 \mathrm{mg}$ \\
\hline Carrier flow rate & $1.0 \mathrm{ml} \mathrm{min}^{-1}$ \\
\hline Sample volume & $130 \mu \mathrm{l}$ \\
\hline Carrier stream & $3 \% \mathrm{v} / \mathrm{v}$ nitric acid \\
\hline Eluent solution & $0.1 \mathrm{M}$ ammonium acetate at $\mathrm{pH} 5.2$ \\
\hline Eluent flow rate & $2.6 \mathrm{ml} \mathrm{min}^{-1}$ \\
\hline Elution time & $3.0 \mathrm{~min}$ \\
\hline
\end{tabular}



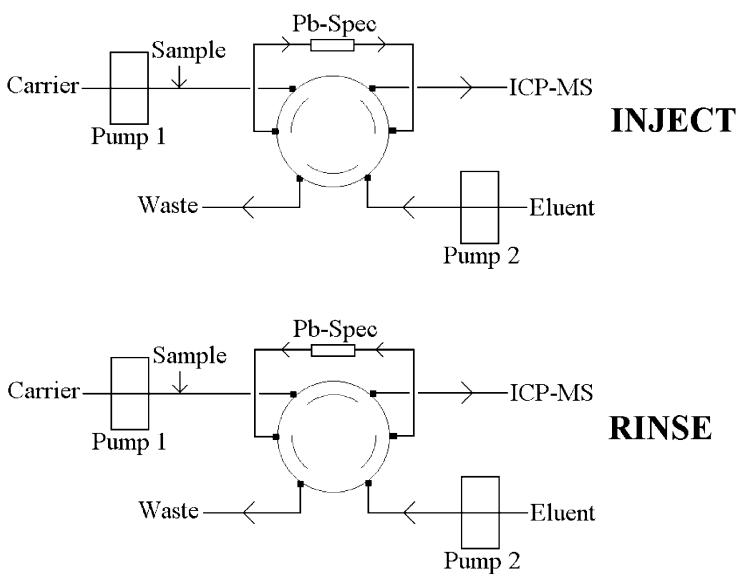

Fig. 1. The flow injection manifold. During the inject step, pump 1 is on and pump 2 is off. The sample is injected into the carrier stream and flows through the column from left to right. During the rinse step, both pumps are on and the column is flushed with eluent from right to left.

The flow rate was set for optimum ICP-MS instrument performance and was not varied.

The glass column was packed with $100 \mathrm{mg}$ of $\mathrm{Pb}$-Spec resin. Glass wool in each end of the column held the material in place. The resin was initially cleaned by pumping $3 \% \mathrm{HNO}_{3}$ through it for $10 \mathrm{~min}$, followed by $20 \mathrm{~min}$ of flushing with 0.1 $\mathrm{M}$ ammonium citrate. A final rinse of $3 \% \mathrm{HNO}_{3}$ for $10 \mathrm{~min}$ completed the process.

Initial experiments were performed to investigate the capacity of the $\mathrm{Pb}-\mathrm{Spec}$. A breakthrough curve was obtained by pumping a solution containing $1000 \mu \mathrm{g} \mathrm{ml}^{-1} \mathrm{~Pb}$ in $2 \% \mathrm{HNO}_{3}$ through the column and into the $1100 \mathrm{~B}$ flame atomic absorption spectrometer. A flow rate of $1.3 \mathrm{ml}$ $\min ^{-1}$ was selected. Data collection began when the solution reached the nebulizer.

The ability of the resin to retain lead as a function of the acidity of the carrier was examined. Nitric acid concentrations of $0.000 \%$, $3.000 \%, 6.375 \%(1 \mathrm{M})$, and $10.00 \%$ by volume were used. The acid content of the sample itself was also varied over a similar range $[2.000 \%$, $3.000 \%, 6.375 \%(1 \mathrm{M})$, and $10.00 \%$ by volume], and the effects on the $\mathrm{Pb}$ peak heights were monitored by the 3100 FAA spectrometer.

The effect of the sample volume was also determined. The heights of the initial breakthrough peaks as well as the eluted peaks were measured as a function of loop size. For this measurement, $1000 \mu \mathrm{g} \mathrm{ml}^{-1} \mathrm{~Pb}$ was injected into the manifold at a flow rate of $5.2 \mathrm{ml} \mathrm{min}^{-1}$. This flow rate was selected for maximum nebulizer efficiency for the 3100 instrument.

The possibility of injecting multiple samples between column rinses was investigated. The 100$\mu \mathrm{g} \mathrm{ml}^{-1} \mathrm{~Pb}$ standard containing the target elements was injected into the manifold repeatedly without subsequent elution. The elements were monitored by ICP-MS.

A qualitative experiment was performed to investigate the possibility of determining additional elements in the bullet samples. It was speculated that by removing the lead matrix without dilution, some trace elements might be detected that were previously below the detection limit of the ICPAES method. Additional elements besides those that were determined in the quantitative procedure, but are known to be present in recycled lead, were added to the qualitative run. The elements that were included were $\mathrm{Ag}, \mathrm{Al}, \mathrm{As}, \mathrm{Bi}, \mathrm{Cd}$, $\mathrm{Cr}, \mathrm{Cu}, \mathrm{Fe}, \mathrm{Ga}, \mathrm{Ge}, \mathrm{Hg}, \mathrm{In}, \mathrm{La}, \mathrm{Ni}, \mathrm{Sb}, \mathrm{Se}, \mathrm{Sn}, \mathrm{Te}$, $\mathrm{Tl}$ and $\mathrm{Zn}$. None of these elements has an ionic radius similar to that of lead [15]. The procedure was changed slightly to accommodate the increased number of elements. The dwell time was decreased from 0.3 to $0.2 \mathrm{~s}$ per mass. This allowed the acquisition of a similar number of points per mass as in the other runs, without generating an unmanageably large data file. No spectral interference corrections were made.

\subsection{Method validation and procedures}

The method was validated by the analysis of NIST reference materials (SRM 2416, bullet lead; SRM 2415, battery lead; and SRM 2417, lead base alloy) and three bullet samples that were prepared by the FBI Laboratory using its current procedure used for ICP-AES. Briefly, an approximately $60-\mathrm{mg}$ sample from the interior of the bullet was weighed to the nearest $0.01 \mathrm{mg}$. The sample was flattened between sheets of plastic and placed in a $15-\mathrm{ml}$ polypropylene centrifuge tube. Six milliliters of $20 \% \mathrm{HNO}_{3}$ were added to the sample, and the capped tube was irradiated in 
a microwave oven for $40 \mathrm{~s}$ on full power. If the sample mass deviated from $60 \mathrm{mg}$, the volume of the $20 \% \mathrm{HNO}_{3}$ was adjusted accordingly to maintain a $10.00-\mathrm{mg} \mathrm{ml}^{-1}$ dilution factor. The sample was then transferred to a conventional oven and heated at $80^{\circ} \mathrm{C}$ for a minimum of $4 \mathrm{~h}$ or until digestion was complete. Ten microliters of $49 \%$ HF were added to the cooled tube followed by vortex mixing. The sample was allowed to sit overnight to ensure complete dissolution. The digest was analyzed by ICP-AES using direct aspiration. The unused portion of the same digest then underwent a final 100 -fold dilution with $2 \%$ $\mathrm{HNO}_{3}$ immediately prior to analysis by ICP-MS.

Sample and standard solutions were injected into the flow injection sample introduction system shown in Fig. 1. Pump 1 was always on and operating with a flow rate of $1.0 \mathrm{ml} \mathrm{min}{ }^{-1}$. In the sample inject mode, pump 2 was off. The data collection was synchronized to begin with the switching of the injection valve. The carrier solution of $3 \% \mathrm{HNO}_{3}$ flushed the sample through the $\mathrm{Pb}-\mathrm{Spec}$ column and into the spectrometer. Once the data collection was completed, the second pump was turned on and the SPE valve turned to the rinse position. The eluent, $0.1 \mathrm{M}$ ammonium citrate, backflushed the column for $3 \mathrm{~min}$ at a flow rate of $2.6 \mathrm{ml} \mathrm{min}{ }^{-1}$. During the elution step, the carrier continued to flow into the ICPMS. When the elution was complete, the valve was returned to the load position and the column was rinsed with the carrier in preparation for the next injection.

Calibration was performed by injecting multielement standards containing matrix-matched lead and $\mathrm{HNO}_{3}$ concentrations. Samples and standards were analyzed in triplicate.

\section{Results and discussion}

\subsection{Variation of system parameters}

The mass of $\mathrm{Pb}-\mathrm{Spec}$ packed into the column was set at $100 \mathrm{mg}$ by preliminary calculations. According to Horwitz et al. [9], the resin capacity is $20.5 \mathrm{mg}$ of $\mathrm{Pb}$ per $\mathrm{ml}$ of bed volume. For a bed density of $0.37 \mathrm{~g} \mathrm{ml}^{-1}$, the capacity is $55.4 \mathrm{mg} \mathrm{Pb}$ retained per gram of resin. The sample digestion procedure initially produces a solution containing $10000 \mu \mathrm{g} \mathrm{ml}^{-1} \mathrm{~Pb}$. Using this concentration and the published capacity of the column, $100 \mathrm{mg}$ of resin should strip the lead from $0.55 \mathrm{ml}$ of sample. This is a common sample volume used in flow injection analysis, so the mass of resin was considered appropriate. The samples were diluted from 10000 to $100 \mu \mathrm{g} \mathrm{ml}^{-1} \mathrm{~Pb}$ so that breakthrough would not accidentally take place.

The Horwitz capacity [9] was based on an offline measurement, but the working capacity of the resin could be significantly different for an on-line experiment. The dynamic capacity of the $\mathrm{Pb}-\mathrm{Spec}$ resin was evaluated by acquiring a breakthrough curve, as shown in Fig. 2. The absorbance signal began to increase from its baseline value at $65 \mathrm{~s}$ and did not reach its maximum value until well after $2 \mathrm{~min}$. This instrument was operated at a flow rate well below its optimum value for maximum sensitivity, and the detection limits of FAAS are much higher than those of ICP-MS. In principle, the column effluent could have been monitored by ICP-MS, but the potential damage to the instrument when the lead broke through the resin prohibited the use of ICP-MS for this experiment. The characterization of the breakthrough curve prior to approximately $65 \mathrm{~s}$ was, therefore, not possible. The sharp rise in lead concentration associated with breakthrough would have been detected at the same time, (i.e. after 2 min of constant sample introduction) regardless of the instrument that was used. Based on this figure, the resin stripped approximately $1.5 \mathrm{mg} \mathrm{Pb}$ from $1.5 \mathrm{ml}$ of solution, corresponding to $15 \mathrm{mg}$ $\mathrm{Pb}$ per gram of resin. A comparison of this value to the Horwitz value of $55.4 \mathrm{mg} \mathrm{Pb}$ for the same mass of resin (see above) indicates the effect of conversion to a flow-through system. Although the on-line capacity is lower than the comparable off-line value, the retention of $1.5 \mathrm{mg}$ of lead is quite satisfactory for the application. Any potential signal suppression caused by the lead that bled through the column before actual breakthrough was examined by ICP-MS in the repeated injection experiment and will be discussed later.

To examine the acid dependency of the metal sorption on the resin, the acid content of both the 


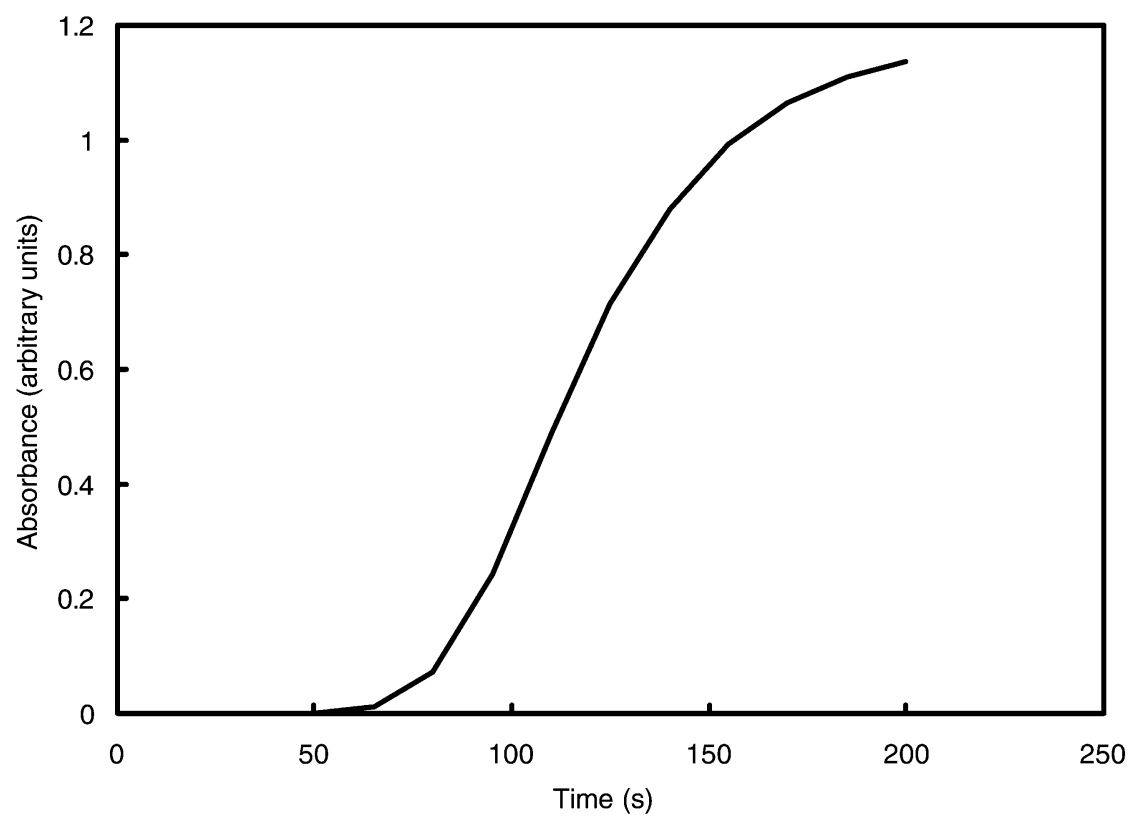

Fig. 2. Breakthrough curve for $1000 \mu \mathrm{g} \mathrm{ml}^{-1} \mathrm{~Pb}$ at a flow rate of $1.3 \mathrm{ml} \mathrm{min}^{-1}$. The curve is the average of three replicate measurements.

sample and the carrier solution were varied. According to Horwitz et al. [9], the lead sorption peaked at an acid concentration of approximately $1 \mathrm{M} \mathrm{HNO}_{3}$. The acid concentrations of the sample and carrier solutions were thus distributed around 1 M. Fig. 3 shows the results. For each sample, the measured absorption was greatest with a carrier acidity of $3 \%$. Though it is possible that the maximum value is achievable at a lower acidity than the minimum tested in this experiment, 3\% was used for the remainder of the study. The differences in absorption for the sam-

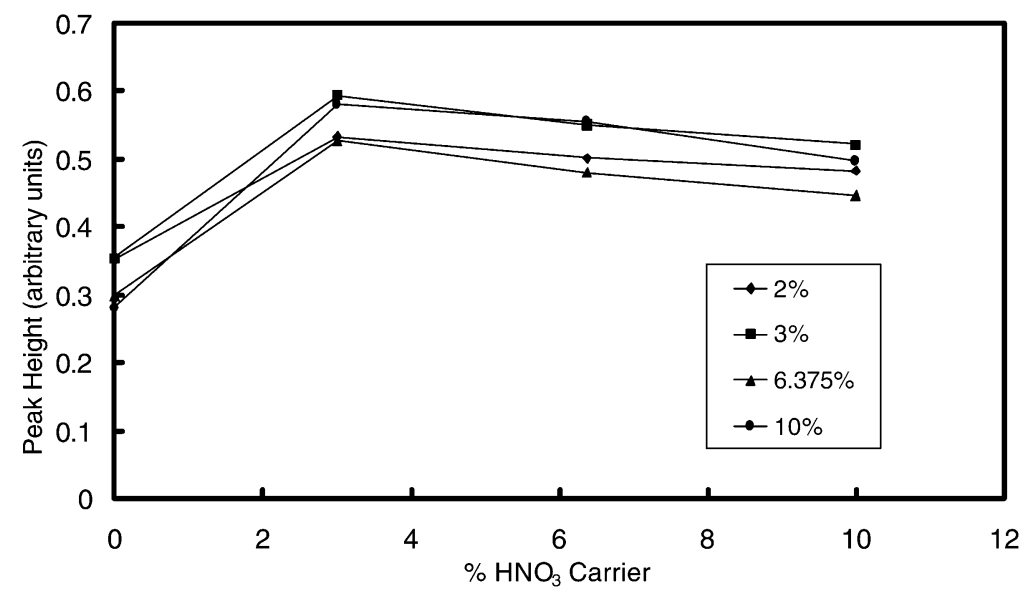

Fig. 3. The effect of varying acid content of both the carrier solution and sample. Samples were individually prepared by dissolving the appropriate amount of lead nitrate in nitric acid. Lead concentrations for each sample were: $2 \% \mathrm{HNO}_{3}, 1000 \mu \mathrm{g} \mathrm{ml}{ }^{-1} ; 3 \%$ $\mathrm{HNO}_{3}, 974 \mu \mathrm{g} \mathrm{ml}^{-1} ; 6.375 \% \mathrm{HNO}_{3}, 971 \mu \mathrm{g} \mathrm{ml}^{-1} ; 10 \% \mathrm{HNO}_{3}, 972 \mu \mathrm{g} \mathrm{ml}^{-1}$. The legend lists the sample acidities as percentages. 
ple acidity, however, do not match the trend observed in the case of the carrier. Although the highest absorption was achieved for sample acidities of $3 \%$ and $10 \% \mathrm{HNO}_{3}$, all values gave acceptable results, so a value of $2 \%$ was selected for the remainder of the experiments. The gain in signal intensity for the $3 \%$ and $10 \%$ samples was not deemed to be sufficiently great to warrant using these concentrations, since maintaining a simple sample preparation procedure was more important.

The effect of sample volume on the results is shown in Fig. 4. The volume of the $1000-\mu \mathrm{g} \mathrm{ml}^{-1}$ sample injected had a significant effect on the efficiency of the lead retention. The peak height absorption of the breakthrough peaks increased with sample volume, as did the absorption of the elution peaks. Although more lead was retained when larger volumes were injected, the amount of lead bleeding through the column increased as well. The only volume for which the breakthrough absorption is zero is the smallest volume, $130 \mu \mathrm{l}$. This suggests that for volumes larger than $130 \mu \mathrm{l}$ the residence time in the column is too short to ensure total retention. Although $130 \mu \mathrm{l}$ was selected as the sample volume for the remainder of the study, it is possible that larger volumes could in fact be used. The amount of lead that breaks through the column may not be enough to cause signal suppression for the target analytes. Again, the choice of value for this parameter involves a compromise: the amount of lead breaking through the column compared to the potential signal augmentation from using a larger sample volume. For this study, minimum lead breakthrough was more important because the detection limit of the ICP-MS was adequate for the determination of the target analytes, even after the dilution caused by dispersion processes in the flow injection manifold.

Further experiments are necessary, however, to characterize the relationship between sample volume and the magnitude of the breakthrough. It is unclear whether this phenomenon is related to the kinetics of the flow-through system, in which case the residence time of the sample within the column is important to ensure complete lead retention. This would suggest that a slower flow rate or a longer, thinner column design would result in more complete adsorption. Another possible explanation may involve the surface characteristics of the resin. In this case, the initial portion of the sample may react with the most easily accessible crown ether cavities, shielding the remaining cavities from the rest of the sample. The column capacity that was observed in the breakthrough experiment suggests that for 1000$\mu \mathrm{g} \mathrm{ml}^{-1}$ solutions, sample volumes much larger

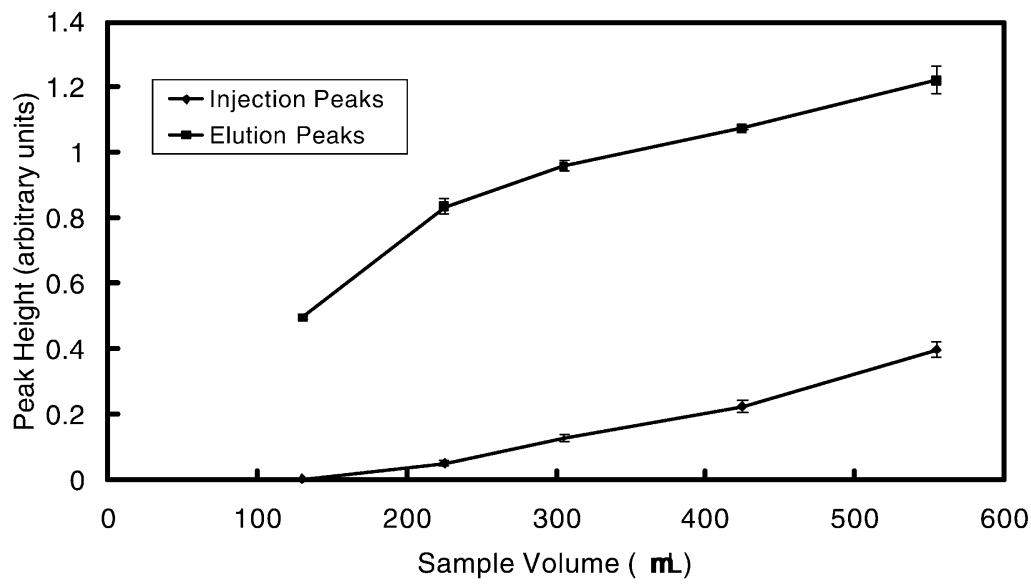

Fig. 4. The effect of changing sample volumes on the heights of breakthrough as well as elution peaks. The top line shows the elutions peak heights, and the lower line shows the heights of the breakthrough peaks. The error bars represent \pm 1 S.D. of the multiple replicates. PE 3100 FAAS detection, $5.2 \mathrm{ml} \mathrm{min}^{-1}$. 
than $130 \mu \mathrm{l}$ could be tolerated by the resin. If the column can really retain $1.5 \mathrm{mg}$ of lead from a flowing stream, then the injection of up to 1500 $\mu l$ should not result in breakthrough. This inconsistency could be caused by the different flow rates used for the breakthrough curve $(1.3 \mathrm{ml}$ $\min ^{-1}$ ) and the sample volume experiments (5.2 $\mathrm{ml} \min ^{-1}$ ). Research is currently underway to answer some of these questions.

\subsection{Analytical performance}

The flow injection solid-phase extraction system was used to remove the lead matrix from a series of calibration standards. Linear calibration plots were fitted to the points generated by the three standards plus a blank using an unweighted least-squares algorithm. The results are given in Table 3. Because the results did not differ significantly between isotopes of a single element, only one isotope is listed for each element. The limit of detection for each element was calculated [16] as the concentration giving a signal equal to three times the root mean square error of the $y$-residuals in the regression analysis.

The limits of detection are in the low $\mathrm{ng} \mathrm{ml}^{-1}$ range. While these values are perfectly adequate for the analysis of bullets, they are higher than typically observed for direct nebulization sample introduction using this ICP-MS instrument. The increased limits of detection may be a consequence of the dilution that occurs in the manifold. One estimate for the on-line dilution, generated by the comparison of the count rate for direct nebulization of an element with its peak maximum value, is approximately 30 -fold. A second estimate, derived from a comparison of the injected volume to an estimated peak volume of $2.0 \mathrm{ml}$, based on the peak basewidth and flow rate, gives a value of approximately 15 -fold. A dilution factor of 15-30 may explain the limits of detection that, although adequate for this application, were rather high. These values may be improved by decreasing the amount of sample dilution in the system.

Because the $\mathrm{Pb}-\mathrm{Spec}$ resin has such a high capacity for lead, injecting samples repeatedly without an intermediate elution step is possible. This would increase sample throughput, since the time required for elution and column rinsing between replicate measurements could be eliminated. The potential disadvantages could be memory effects or signal suppression caused by lead bleeding through the column before breakthrough. The ${ }^{208} \mathrm{~Pb}$ signals for repeated injections are shown in Fig. 5. The lead background increased with each injection, demonstrating that although the column was retaining the lead some column bleed occurred. Fig. 6 shows the effect of repeated injections on the ${ }^{107} \mathrm{Ag}$ peak, which was used here as a model for the other elements. As the number of injections increased, the ${ }^{107} \mathrm{Ag}$ peak remained essentially unchanged. Minor variations in the peak appearance occurred, but the R.S.D. $(n=5)$ of the peak area was less than $3.2 \%$. Similar peak area precisions were observed for the other elements. This demonstrates that the amount of lead bleeding off the column was not

Table 3

Calibration equation variables for selected isotopes

\begin{tabular}{lcccc}
\hline Element & $\begin{array}{l}\text { Slope }^{\mathrm{a}} \\
(\text { counts ng }\end{array}$ & $\begin{array}{l}\text { Intercept }^{\mathrm{a}} \\
(\text { counts })\end{array}$ & $\begin{array}{l}\text { Correlation } \\
\text { coefficient }\end{array}$ & $\begin{array}{l}\text { LOD } \\
\left(\mathrm{ng} \mathrm{ml}^{-1}\right)\end{array}$ \\
\hline${ }^{63} \mathrm{Cu}$ & $446 \pm 33$ & $330 \pm 2100$ & 0.9997 & 4 \\
${ }^{75} \mathrm{As}$ & $91 \pm 7$ & $43 \pm 330$ & 0.9997 & 3 \\
${ }^{107} \mathrm{Ag}$ & $426 \pm 61$ & $-68 \pm 390$ & 0.9989 & 0.8 \\
${ }^{111} \mathrm{Cd}$ & $97 \pm 7$ & $14 \pm 23$ & 0.9997 & 0.2 \\
${ }^{118} \mathrm{Sn}$ & $242 \pm 2$ & $130 \pm 150$ & 1.0000 & 0.6 \\
${ }^{121} \mathrm{Sb}$ & $240 \pm 6$ & $-713 \pm 3800$ & 0.9999 & 10 \\
${ }^{209} \mathrm{Bi}$ & $429 \pm 55$ & $540 \pm 3500$ & 0.9991 & 7 \\
\hline
\end{tabular}

\footnotetext{
${ }^{\mathrm{a}}$ The \pm terms are $95 \%$ confidence intervals calculated according to the procedure described by Miller and Miller [16] for four calibration points, each of which is the mean of three replicate measurements.
} 


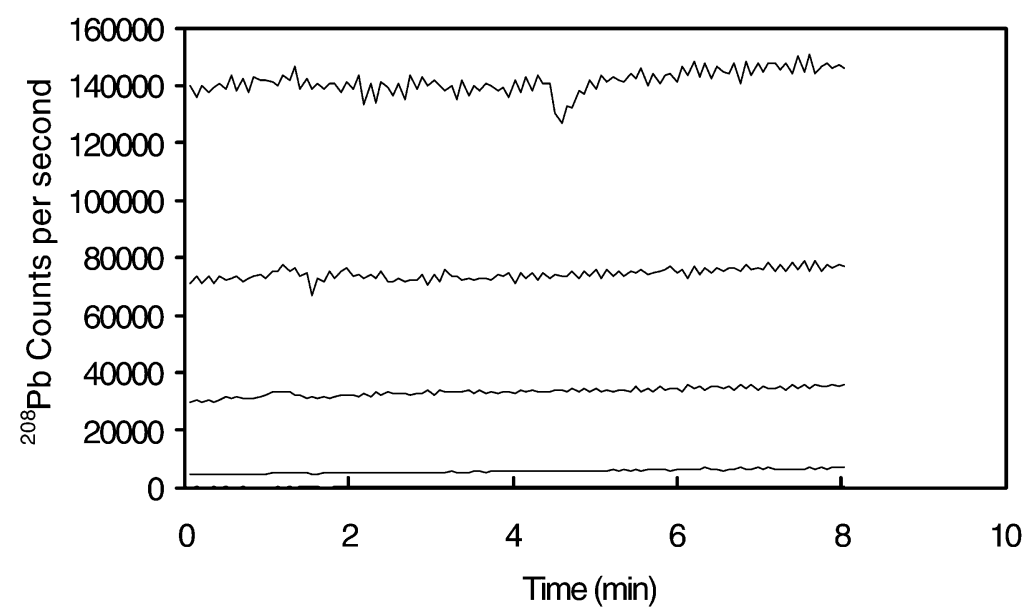

Fig. 5. The ${ }^{208} \mathrm{~Pb}$ signals for sample injections $1,4,7,10$ and 13 , numbered from the bottom of the plot. The trace for injection 1 is along the baseline, and that for injection 13 is the top line. The lead background increases steadily, but breakthrough is not observed. The sudden signal drop in injection 13 is due to noise.

sufficient to cause signal suppression of the target analytes. Although the number of injections was halted at 13 , additional injections could have been made. The breakthrough point of the column was not attained, since the $\mathrm{Pb}$ signal did not increase as shown in Fig. 2. Each injection of $130 \mu \mathrm{l}$ of 100 $\mu \mathrm{g} \mathrm{ml}^{-1} \mathrm{~Pb}$ contained $13 \mu \mathrm{g}$ of $\mathrm{Pb}$. The column was capable of retaining 13 injections, or $169 \mu \mathrm{g}$ of $\mathrm{Pb}$. Because the column did not reach breakthrough, the working capacity of the column is greater than $169 \mu \mathrm{g}$. The working capacity of the column may be as high as its calculated capacity of $1.5 \mathrm{mg}$, but it is possible that the lead bleeding from the column would be enough to cause signal suppression before the column capacity is reached.

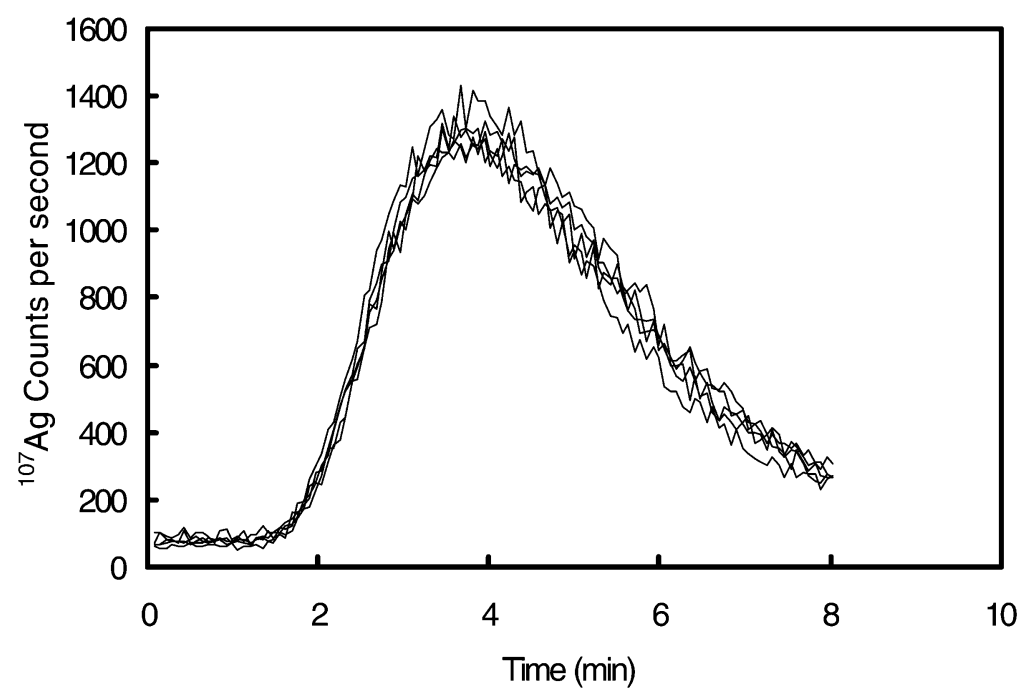

Fig. 6. The ${ }^{107} \mathrm{Ag}$ signal for sample injections $1,4,7,10$ and 13. Although the lead background increases with each injection, the effect on the silver peak is minimal. 
The peaks obtained by the flow injection SPE technique for most elements had basewidths of approximately $1.5 \mathrm{~min}$. The $\mathrm{Ag}$ peaks were broader, having basewidths of nearly $6.5 \mathrm{~min}$. This is illustrated in Fig. 7, which shows the overlay of one ${ }^{107} \mathrm{Ag}$ peak from Fig. 6 with the corresponding ${ }^{63} \mathrm{Cu}$ peak from the same sample injection. The $\mathrm{Ag}$ peak basewidth is approximately four times greater than that of the $\mathrm{Cu}$ peak. Although the peak areas were reproducible, the time required for the analytes to pass through the system was long, resembling a typical chromatography experiment rather than a flow injection one. The peaks for most analytes in the sample analyzed were easily integrated, but on occasion, some elements were below the limits of detection. By decreasing the broadening, it may be possible to determine these elements. Further developments of the system are in progress, including an examination of the effect of column size.

One column was used daily for 5 months, during which time several hundred injections were made, without any loss of performance. Column lifetime was not determined in this study because it was never reached.

\subsection{Results for samples}

The results of the analysis of three SRMs are shown in Table 4. Two samples of each SRM were separately digested and analyzed in triplicate. The elemental concentrations are expressed as the mean together with the $95 \%$ confidence interval for each value in parentheses. The concentrations that were calculated for each isotope of a specific element did not differ significantly from one another, so results for only one isotope are shown for each element. The value of the uncertainty for the SRMs, also shown in parentheses, is the value from the certificate. Since this value is estimated, it is impossible to perform any statistical test to determine whether the concentrations are significantly different. As an approximate basis for judgment, however, the concentrations can be assumed to be indistinguishable if the mean of one falls within the confidence interval about the other. Twenty-eight of the possible

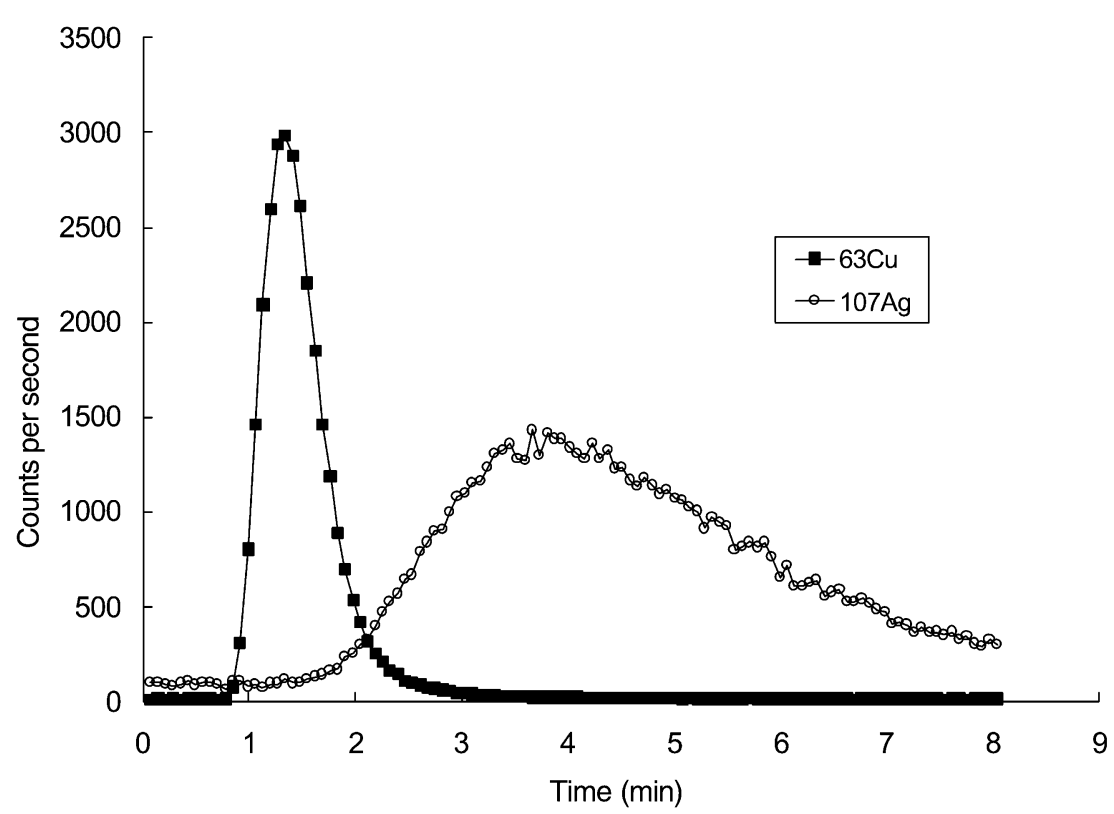

Fig. 7. The peaks for ${ }^{63} \mathrm{Cu}$ and ${ }^{107} \mathrm{Ag}$ from the first of the repeated injections. The signal for ${ }^{63} \mathrm{Cu}$ has been divided by a factor of 20 to match the scale of ${ }^{107} \mathrm{Ag}$. The width of the silver peak is approximately four times that of the copper peak. 
Table 4

Concentrations of the trace elements in NIST standard reference materials after lead removal

\begin{tabular}{|c|c|c|c|c|c|c|c|c|c|}
\hline \multirow[t]{2}{*}{ Element } & \multicolumn{3}{|c|}{ SRM 2416, Bullet Lead } & \multicolumn{3}{|c|}{ SRM 2415, Battery Lead } & \multicolumn{3}{|c|}{ SRM 2417, Lead-based Alloy } \\
\hline & Certified & Sample A & Sample B & Certified & Sample A & Sample B & Certified & Sample A & Sample B \\
\hline${ }^{63} \mathrm{Cu}$ & $650(20)$ & $660(60)$ & $640(20)$ & $950(50)$ & $940(30)$ & $940(50)$ & $100(10)$ & $110(10)$ & $95(4)$ \\
\hline${ }^{75} \mathrm{As}$ & $560(10)$ & $540(20)$ & $520(30)$ & $2000(100)$ & $1900(40)$ & $1880(190)$ & $110(10)$ & $130(10)$ & $120(10)$ \\
\hline${ }^{107} \mathrm{Ag}$ & $44(2)$ & $39(3)$ & $35(3)$ & $20(10)$ & $23(4)$ & $11(4)$ & $100(10)$ & $93(4)$ & $86(7)$ \\
\hline${ }^{111} \mathrm{Cd}$ & $2^{a}$ & 1.1 & $1(1)$ & $20(10)$ & $21.3(0.4)$ & $24(5)$ & $<2^{\mathrm{a}}$ & ND & ND \\
\hline${ }^{118} \mathrm{Sn}$ & $900(100)$ & $730(110)$ & $700(40)$ & $3300(100)$ & $2830(250)$ & $2820(240)$ & $70(20)^{\mathrm{b}}$ & $50(20)$ & $42(6)$ \\
\hline${ }^{121} \mathrm{Sb}$ & $7900(100)$ & $7620(370)$ & $7500(140)$ & $29500(400)$ & $28280(800)$ & $28980(2640)$ & $100(10)$ & $170(50)$ & $104(5)$ \\
\hline${ }^{209} \mathrm{Bi}$ & $1000(100)$ & $990(50)$ & $920(50)$ & $540(40)$ & $537.9(0.6)$ & $500(50)$ & $100(10)$ & $98(3)$ & $78(6)$ \\
\hline
\end{tabular}

Concentrations are in $\mathrm{mg} \mathrm{g}^{-1}$ in the solid sample. Values in parentheses are $95 \%$ confidence intervals for three replicate measurements for the experimental values, but are estimated uncertainties in the certified values. ND: Not detected.

${ }^{a}$ Reference value, not certified.

${ }^{\mathrm{b}}$ Value obtained through repeated measurement, not certified. 
42 comparisons met this criterion and for a further six comparisons, the confidence intervals overlapped. For eight comparisons, the confidence intervals did not overlap. The element with the highest degree of inaccuracy was tin.

The method was also used to determine the trace elements in some real samples. Table 5 gives the results for the analysis of three bullets by both ICP-MS and ICP-AES. A two-point calibration curve was used, with SRM 2416 as the high concentration for each element and a blank solution as the low concentration. A two-point calibration is standard procedure for the FBI Laboratory's ICP-AES method, so a similar calibration was applied to the ICP-MS method. The ICP-MS calibration used a $3 \% \mathrm{HNO}_{3}$ solution as the blank. The ICP-AES procedure used a highpurity lead solution as the low concentration standard for the target elements. Table 5 shows that the elemental concentrations obtained by both techniques are similar. A regression analysis in which the ICP-MS data were plotted vs. the ICPAES data gave a line of slope $1.01 \pm 0.04$ and intercept $-5 \pm 100 \mu \mathrm{g} \mathrm{g}^{-1}$. The uncertainties represent the $95 \%$ confidence interval [16]. It is possible that some of the differences in individual concentrations are caused by the use of different blank solutions in the calibration. Of the 21 possible comparisons of precisions, there are no significant differences between the ICP-AES results and those of the ICP-MS method ( $F$-test, 95\% confidence) for 16 of the comparisons. The dif- ferences that were observed could be the result of instrumental drift: triplicate emission measurements were made over a 30 -s period, whereas the triplicate mass spectral measurements were made over approximately $24 \mathrm{~min}$.

To evaluate the possibility of additional discrimination capability provided by increasing the number of analytes, the digest of bullet Q1a was analyzed qualitatively by ICP-MS. The elements currently utilized for bullet lead characterization were selected based on ICP-AES and NAA studies. The source discrimination capability of each element is a function of a number of factors including homogeneity within a source, variability across sources, and precision of the analytical method. One potential advantage of ICP-MS as a detection method is that additional elements may fit the third of these criteria, i.e. can be determined with good analytical precision.

As ICP-MS is a rapid sequential measurement system, increasing the number of elements measured has consequences in terms of the number of points per peak collected. However, if 20 points per peak are taken to give good accuracy and precision (i.e. absence of spectral skew), then for a combined settling and dwell time of approximately $50 \mathrm{~ms}$ up to 60 isotopes could be measured for a peak of $60 \mathrm{~s}$ basewidth [17].

Of the 20 additional elements (Ag, Al, As, Bi, $\mathrm{Cd}, \mathrm{Cr}, \mathrm{Cu}, \mathrm{Fe}, \mathrm{Ga}, \mathrm{Ge}, \mathrm{Hg}, \mathrm{In}, \mathrm{La}, \mathrm{Ni}, \mathrm{Sb}, \mathrm{Se}, \mathrm{Sn}$, $\mathrm{Te}, \mathrm{Tl}$ and $\mathrm{Zn}$ ) that were tested in the qualitative run (15 points per peak), only $\mathrm{Al}, \mathrm{Ga}, \mathrm{La}, \mathrm{Ni}$ and

Table 5

Concentrations of the trace elements in forensic bullet samples, determined by ICP-MS after lead removal and ICP-AES without lead removal

\begin{tabular}{|c|c|c|c|c|c|c|}
\hline \multirow[t]{2}{*}{ Element } & \multicolumn{2}{|l|}{ K1a } & \multicolumn{2}{|l|}{$\mathrm{K} 2 \mathrm{a}$} & \multicolumn{2}{|l|}{ Q1a } \\
\hline & SPE-ICP-MS & ICP-AES & SPE-ICP-MS & ICP-AES & SPE-ICP-MS & ICP-AES \\
\hline${ }^{63} \mathrm{Cu}$ & $400(28)$ & $404(8)$ & $554(15)$ & $573(31)$ & $554(35)$ & $573(11)$ \\
\hline${ }^{75} \mathrm{As}$ & $31(10)$ & 21(1) & $33(2)$ & $35(4)$ & $40(7)$ & $40(1)$ \\
\hline${ }^{107} \mathrm{Ag}$ & $21.9(0.1)$ & $26.2(0.3)$ & $26(1)$ & $30(2)$ & $26.4(0.6)$ & $30(1)$ \\
\hline${ }^{111} \mathrm{Cd}$ & $0.1,0.6^{\mathrm{a}}$ & $0.25(0.01)$ & $1(2)$ & $1.6(0.1)$ & $3(1)$ & $2.2(0.1)$ \\
\hline${ }^{118} \mathrm{Sn}$ & $16(9)$ & ND & ND & ND & $1.4(0.2)$ & $1(1)$ \\
\hline${ }^{121} \mathrm{Sb}$ & 8561 (686) & $8323(150)$ & $6632(340)$ & $6830(340)$ & 7037 (300) & 6979 (123) \\
\hline${ }^{209} \mathrm{Bi}$ & $100.8(0.6)$ & $93(6)$ & $106(2)$ & $107(3)$ & $117(16)$ & $104(3)$ \\
\hline
\end{tabular}

Concentrations are in $\mathrm{mg} \mathrm{g}^{-1}$ in the solid sample. Values in parentheses are $95 \%$ confidence intervals for three replicate measurements of each lead digest solution. ND: Not detected.

${ }^{\mathrm{a}}$ Two replicates. 
$\mathrm{Zn}$ were detected in the bullet. Each of these elements was detected as a discernable peak, although the role of spectral interferences has yet to be investigated. The Ga peak was broader than the others, suggesting that $\mathrm{Ga}$ was slightly retained by the column, despite the fact that its radius at $62 \mathrm{pm}$ is smaller than that of $\mathrm{Pb}$ at 119 pm [15]. It is possible that the procedure is capable of detecting additional elements in bullets that were not present in this specific sample. For example, Keto [2] reports the successful determination of Te in NIST SRM 2416. Further studies are needed to determine the resin retention characteristics of any additional elements, as well as their variation among lead sources.

\section{Conclusions}

It is concluded that it is possible to remove the high concentration of lead in bullet digests by on-line, solid-phase extraction with $\mathrm{Pb}$-Spec to an extent that allows determination by ICP-MS of the trace elements commonly used in forensic comparisons. This suite of elements could be extended to include $\mathrm{Al}, \mathrm{Ga}, \mathrm{La}, \mathrm{Ni}$ and $\mathrm{Zn}$, although the forensic utility of these additional elements has yet to be determined. The procedure developed is not yet fully optimized, as the factors governing the dynamic capacity of the column have not been unambiguously resolved and the dispersion in the manifold could be reduced, thereby decreasing peak widths and improving the signal-to-noise ratio. Further studies of these factors are in progress. It is anticipated that the performance of an SPE-ICP-MS procedure will ultimately complement that of the current ICP-AES method.

\section{Acknowledgements}

The authors thank Dr Diana Grant of the FBI Laboratory for digesting the lead samples, performing the ICP-AES analysis, and providing results for comparison. We also thank Dr JoAnn Buscaglia of the FBI Laboratory's Forensic Science Research Unit for her invaluable assistance.
Technical support by Dr Ela Bakowska of Agilent Technologies, Inc. is also gratefully acknowledged. We thank Eichrom, Inc. for the donation of $\mathrm{Pb}$-Spec resin and the Schering-Plough Research Institute for financial support for $\mathrm{E}$. Yourd.

\section{References}

[1] E.R. Peele, D.G. Havekost, C.A. Peters, J.P. Riley, R.C. Halberstam, R.D. Koons, Comparison of bullets using the elemental composition of the lead component. Proceedings of the International Symposium on the Forensic Aspects of Trace Evidence (June 1991) 57-68.

[2] R.O. Keto, Analysis and comparison of bullet leads by inductively-coupled plasma mass spectrometry, J. For. Sci. 44 (1999) 1020-1026.

[3] Y. Suzuki, Y. Marumo, Determination of trace impurities in lead shotgun pellets by ICP-MS, Anal. Sci. 12 (1996) 129-132.

[4] P. Becotte-Haigh, J.F. Tyson, E. Denoyer, Flow injection manifold for matrix removal in inductively coupled plasma mass spectrometry by solid phase extraction: determination of $\mathrm{Al}, \mathrm{Be}, \mathrm{Li}$, and $\mathrm{Mg}$ in a uranium matrix, J. Anal. At. Spectrom. 13 (1998) 1327-1331.

[5] J.D. Lamb, M.D. Christenson, Macrocyclic ligands in separations, J. Incl. Phenom. Mol. Recognit. Chem. 32 (1998) 107-119.

[6] J.S. Bradshaw, R.M. Izatt, Crown ethers: the search for selective ion ligating agents, Acc. Chem. Res. 30 (1997) 338-345.

[7] J.D. Lamb, R.M. Izatt, P.A. Robertson, J.J. Christensen, Highly selective membrane transport of $\mathrm{Pb}^{2+}$ from aqueous metal ion mixtures using macrocyclic carriers, J. Am. Chem. Soc. 102 (1980) 2452-2454.

[8] S. Dernini, A. Scrugli, S. Palmas, A.M. Polcaro, Competitive extraction of $\mathrm{Pb}^{2+}$ by dicyclohexano-18-crown-6 from heavy metal aqueous solutions, J. Chem. Eng. Data 41 (1996) 1388-1391.

[9] E.P. Horwitz, M.L. Dietz, S. Rhoads, C. Felinto, N.H. Gale, J. Houghton, A lead-selective extraction chromatographic resin and its application to the isolation of lead from geological samples, Anal. Chim. Acta 292 (1994) 263-273.

[10] N.H. Gale, A new method for extracting and purifying lead from difficult matrices for isotopic analysis, Anal. Chim. Acta 332 (1996) 15-21.

[11] E.P. Horwitz, M.L. Dietz, D.E. Fisher, Separation and preconcentration of strontium from biological, environmental, and nuclear waste samples by extraction chromatography using a crown ether, Anal. Chem. 63 (1991) $522-525$

[12] X.P. Yan, M. Sperling, B. Welz, Application of a macrocycle immobilized silica gel sorbent to flow injection on-line microcolumn preconcentration and separation 
coupled with flame atomic absorption spectrometry for interference-free determination of trace lead in biological and environmental samples, Anal. Chem. 71 (1999) 4216-4222.

[13] T. Seki, H. Takigawa, Y. Hirano, Y. Ishibashi, K. Oguma, On-line preconcentration and determination of lead in iron and steel by flow injection-flame atomic absorption spectrometry, Anal. Sci. 16 (2000) 513-516.

[14] P. Sooksamiti, H. Geckeis, K. Grudpan, Determination of lead in soil samples by in-valve solid-phase extraction-flow injection flame atomic absorption spectrometry, Analyst 121 (1996) 1413-1417.
[15] R.D. Shannon, C.T. Prewitt, in: J.A. Dean (Ed.), Lange's Handbook of Chemistry, McGraw-Hill, Inc, New York, 1992, pp. 4.12-4.17.

[16] J.C. Miller, J.N. Miller, Statistics for Analytical Chemistry, 3rd ed, Ellis Horwood PTR Prentice Hall, New York, 1993, pp. 101-139.

[17] J.F. Tyson, FIA techniques and strategies expand the potential of atomic spectrometry, in: A. Sanz-Medel (Ed.), Flow Analysis with Atomic Spectrometric Detectors, Chapter 3, Elsevier, Amsterdam, 1999, pp. 64-97 and references therein. 